\title{
Contribuição ao estudo da história do direito brasileiro $(*)$
}

\section{Valdomiro Lobo da Costa}

1. A importância do estudo da história do direito não pode ser subestimada. Ninguém chegará, realmente, a conhecer a fundo as instituições jurídicas, se não procurar descobrir-lhes as origens históricas, a fim de acompanharlhes a evolução e as transformações através dos tempos, de maneira a bem lhes apreender o sentido e a extensão no momento em que as examina.

Entre nós, sem embargo de tão elementar princípio, o estudo sistemático da disciplina objeto destas despretenciosas considerações não tem merecido a juristas e legisıdores o cuidado que, em geral, uns e outros costumam dispensar a todos os demais ramos da ciência jurídica.

Escassa é a bibliografia que possuimos do assunto e, a respeito das medidas legislativas destinadas a assegurar continuidade ao ensino da matéria nos cursos jurídicos do país, o que se nota é a insegurança do legislador brasileiro quanto à exata conveniência didática de incluir nos programas oficiais, a cargo de cadeira autônoma, a difusão de tais conhecimentos especializados.

2. A disciplina foi lecionada pela primeira vez, nas Faculdades de Direito de São Paulo e de Olinda, mercê da reforma do ensino superior contida no Decreto n. 9460, de

( ${ }^{\star}$ Trabalho apresentado ao prof. Waldemar Ferreira, no curso de doutorado, em 1952. 
17 de janeiro de 1885, que lhe atribuiu posição de igualdade no quadro das matérias constitutivas do curso regular de bacharelado. Curta duração teve, entretanto, o seu ensino: menos de dez mêses depois, a lei que o tornara obrigatório foi revogada pelo decreto $n$. 9522 , de 28 de novembro, e a congregação da Faculdade de Direito de São Paulo, incumbida de redigir novo projeto de estatutos do ensino jurídico, dêle não mais cogitou.

Proclamada a República, a refórma de Benjamin Constant (decreto n. 1232-H, de 2 de janeiro de 1891), restabeleceu a obrigatoriedade da matéria, a ser estudada juntamente com a filosofia do direito, introduzida nos cursos em substituição à cadeira de direito natural.

Nova refórma do ensino, operada pela lei n. 314, de 30 de outubro de 1895, determinou a separação das duas disciplinas em cátedras distintas, mantendo a de filosofia do direito na primeira série do curso e a de história do direito, especialmente do direito nacional, no último ano, ao lado da de legislação comparada, até que a refórma de Epitácio Pessôa, ordenada pelo decreto n. 3903, de 12 de janeiro de 1901, suprimiu a cadeira de história, a qual não foi restabelecida nem mesmo quando, pelo decreto n. 19.851, de 11 de abril de 1931, se instituiu no Brasil o sistema universitário com a criação do curso de doutorado.

Coube ao Estado de São Paulo, na organização da sua atual Universidade, sob o govêrno do saudoso paulista Armando de Salles Oliveira, restituir à disciplina a devida dignidade didática, inscrevendo-a por fôrça dos estatutos aprovados pelo decreto federal n. 39 , de 3 de setembro de 1934, entre as cadeiras constitutivas do primeiro ano do curso de doutorado.

Assume, assim, a história do direito pátrio, afinal, depois de tantos anos de criminosa proscrição legislativa, o relevante papel que a enciclopédia jurídica lhe assina, de indispensável coroamento da cultura dos estudiosos do direito. 
3. Tão prolongada ausência de obrigatoriedade do estudo da matéria houvera de gerar, necessariamente, o desinterêsse dos escritores nacionais pelas árduas pesquisas que ela exige.

E é o que tem acontecido, com sensivel prejuizo das nossas letras jurídicas, de regra tão ricas nos restantes departamentos do direito, e aflitiva contingência em que se encontram, para cumprirem o regulamento vigente, os candidatos às provas preparatórias da conquista da borla doutoral.

Na primeira centúria da instalação dos cursos jurídicos no Brasil, afóra artigos esparsos, conferências e memórias publicadas em jornais e revistas, uma única obra sistemática foi dada à estampa, em 1895: a História do direito nacional, de Martins Junior, lente catedrático da Faculdade de Direito de Recife, prefaciada pelo professor Andrade Bezerra.

A seguir, na ordem cronológica, são publicadas, em 1933, pela Tipografia da Emprêsa do Anuário Comercial, em Lisboa, com o título de As diretrizes do direito mercantil brasileiro, as magistrais lições proferidas pelo professor Waldemar Martins Ferreira, na sala dos atos grandes da Faculdade de Direito da Universidade de Lisboa, por ocasião do seu exílio em Portugal. Nelas se compendia tôda a história do nosso direito comercial.

Em 1936 e 1947 aparecem, respectivamente, o $10^{\circ}$ e $2 .^{\circ}$ volumes dos interessantes ensaios de autoria do $\mathrm{dr}$. Cesar Tripoli, publicados com a denominação de História do direito brasileiro, abrangendo o estudo do direito no Brasil no periodo que vai do descobrimento à fase da maioridade, no segundo Império. $O$ falecimento do autor impediu que o trabalho se concluisse, permanecendo, por isto, até agora, à espera do jurista de têmpera, que retome o fio às buscas interrompidas e se faça o historiador das épocas ulteriores, em que o direito pátrio adquire feição verdadeiramente nacional e ascende, pelos méritos inconfundiveis de culto- 
res imortais, a posições de extraordinário realce no cenário jurídico universal.

Reaberto, em 1951, o curso de doutorado, nêle profere o infatigavel catedrático da matéria em São Paulo, professor Waldemar Martins Ferreira, durante o primeiro semestre, as eruditas preleções que a Livraria Freitas Bastos acaba de editar, compreendendo a História do direito brasileiro até a reversão das capitanias à corôa portuguêsa e os novos rumos da colónia.

É tudo quanto existe.

Cesar Tripoli, em seu mencionado livro, anota as várias publicações, sem carater sistemático, feitas sôbre assuntos de história do direito, em diferentes épocas, por escritores de pról, muitas delas contendo mesmo preciosos subsídios a que, forçosamente, hão de recorrer quantos pretendam aprimorar os seus conhecimentos da matéria.

Ha nele, entretanto, duas lamentaveis omissões: esquece a douta monografia L'évolution du droit civil au Brésil de 1869 a 1919, com que o insigne Clovis Bevilaqua ilustrou, em benefício dos estudiosos da história do direito brasileiro, as páginas do Livre du cinquantenaire de la Société de Législation Comparée, de Paris, e não refere a valiosa contribuição trazida aos mesmos estudos pela dissertação de concurso do professor Benedito Siqueira Ferreira, $D a$ natureza jurídica da ação, já publicada por ocasião do aparecimento do segundo volume da sua obra inacabada.

Uma e outra completam a relação, pouco numerosa, mas seléta, dos autores que entre nós têm versado, com autoridade, a história geral ou particular das instituições jurídicas brasileiras.

4. Com excepção de Martins Junior, que à sua obra intitula História do direito nacional, todos os mais preferem a denominação de História do direito brasileiro, inclusive o professor Benedito Siqueira Ferreira, no capítulo III, em que, sob a epígrafe Formação do nosso direito, remonta, 
com erudição e brilho, a épocas secularmente afastadas do começo da nacionalidade.

Dado que à lei não se deve atribuir o emprêgo errado de expressões técnicas e haja, no Brasil, sempre chamado História do direito nacional à cadeira de cujo objeto estamos cuidando, poderia parecer à primeira vista ter tido o legislador em mente estatuir a abrigatoriedade apenas do estudo da história do direito propriamente nacional, isto é, imperante no Brasil desde a constituição jurídica do estado brasileiro, ou seja da sua elevação à categoria de reino.

Tal não é, todavia, a inteligência que convém ao restritivo do texto legal e que, sem excluir o mesmo professor Martins Junior, todos lhe emprestam.

De fato: embora use o adjetivo nacional, é das origens remotas do direito português que trata o mestre pernambucano para explicar a formação do direito brasileiro.

5. Unânime, a respeito, a opinião dos autores: a história do direito brasileiro há que ser estudada na história do direito português, pois uma e única fonte é que deu origem ao direito dos dois povos.

Diz o professor Waldemar Martins Ferreira, em sua História do direito brasileiro (p. 23, n. 8) : Por mais paradoxal que pareça, a história do direito brasileiro é muito mais antiga do que a história do Brasil. Se esta começa, vista pelo prisma do descobrimento, no século XVI, ou seja em 1500, a história do direito brasileiro confunde-se, nos seus primórdios, como em grande parte de seu desenvolvimento, com o direito português. Foi êste o que vigorou no Brasil desde que começou a colonizar-se pelos descobridores."

Escreve Martins Junior (ob. cit., p. 144): "O português entrou para o Brasil, pela porta do tratado de Tordesilhas, na qualidade de senhor, de dono, de proprietário. Instalando-se em sua nova possessão e tendo de realizar vis-a-vis do selvagem o processo de luta social a que Novicow chama de eliminação biológica, êle trouxe à terra 
descoberta e para seu uso, toda a sua bagagem legislativa, como trouxe os seus costumes, os seus escravos, as suas roupas e jóias. Transportava-se para cá um pedaço da nacionalidade portuguêsa; era natural que viessem com êle as leis respectivas, como parte que eram do patrimônio moral da metrópole. Assim o direito que ia vigorar na colónia não tinha que nascer do choque de interesses das populações postas em contacto: era um direito que estava feito e que precisava simplesmente ser aplicado, depois de importado."

O professor Benedito Siqueira Ferreira (ob. cit., p. 31 e seguintes), adotando a classificação de Levy Ulmann, divide as legislações modernas em três categorias: povos de legislação escrita, nos quais a evolução se opera por via de costume (Inglaterra); povos que têm códigos e de evolucão legislativa (paises continentais da Europa e sul americanos); e povos de legislação de indole religiosa tal, que impede a sua evolução, como a muçulmana. Filia o direito português ao grupo, na segunda categoria, dos povos cujo direito se origina dos direitos romano, bárbaro e canônico. Acrescenta: "Nosso direito se constituiu, pois, através de Portugal, tendo em seus alicerces, o Corpus juris romanorum, o Corpus juris canonici, editado por Walter em 1824, composto de várias leis das diversas tribus bárbaras: francos, burgundios visigodos, saxões, etc e o Corpus juris canonici, reunião das Decretais de Graciano, de Gregório IX, Liber Sextus Decretalium, das Clementinas ou Decretais de Clemente V e das Extravagantes comuns e de João XXII." $\left({ }^{\star \star}\right)$.

${ }^{*}$ ) A primeira referência, no trecho transcrito, ao Corpus juris canonici, resulta de evidente lapso de revisão: é ao Corpus juris germanici que o festejado mestre remete o leitor.

$\left(^{* *}\right.$ Graciano, frade beneditino do mosteiro de S. Felix, em Bolonha (século XII), é autor da coleção sistemática das leis eclesiásticas, conhecidas sob o nome de decretum (também chamada Corpus juris canonici). As. Decretais é que são de Gregório IX. 
Cesar Tripoli (ob. cit, p. 30), conquanto em seu método de exposição relegue a segundo plano a questão das fontes remotas e divida o estudo da matéria em períodos históricos a partir do descobrimento do Brasil, não deixa, contudo, de atribuir ao direito brasileiro a mesma origem do direito português, reconhecendo-lhes matriz comum nos direitos romano e canônico.

6. Diverge dêste ponto de vista o eminente Enrico Tullio Liebman.

Em recente artigo doutrinário, inserto na coletânea de trabalhos jurídicos publicada em honra do professor Enrico Redenti, afirma o notavel processualista não provir o direito português, como todo o direito da península ibérica, de qualquer ou dos três grandes códigos a que é costume filiá-lo, mas direta e precipuamente do direito comum que regeu a Europa inteira na época intermédia e lhe assegurou, durante séculos, a unidade jurídica, emigrando no século XVI para a América Latina, onde, sobretudo nos paises mais distantes e de formação mais recente, "si é conservato più genuino fin nei tempi moderni" (Istituti del diritto comune nel processo civile brasiliano, pp. 581 a 607, in studi in onore di Enrico Redenti, nel XL anno del suo Insegnamento, Milão, 1951).

Convida os juristas italianos a que se voltem com maior interêsse para o direito das nações do Novo Mundo, não só pelos vínculos de "comune civilità e da stretti rapporti di commercio e di affetti, destinati a divenire sempre più frequenti e profondi", que as prendem à itália, como por que a isso "si aggiunge il fatto che le istituzioni giuridiche di queste nazioni derivano anch'esse direttamente dal grande tronco del Diritto Comune europeo dell'epoca intermedia; e che perciò il loro studio non solo ci permette di allargare $i$ nostri orizzonti e di arricchire la nostra esperienza, ma ci fa avere in particolare una maggiore conoscenza delle sorti toccate a un diritto che fu grande parte della nostra tradizione giuridica e un quadro più completó 
delle varie vie per le quali si è frantumata e frazionata l'antica unità giuridica dell'Europa dei secoli passati."

Nestas ordenações jurídicas - acrescenta o insigne escritor - encontramos, muitas vezes quase intactos, "numerosi istituti del nostro diritto intermedio che da noi sono da tempo scomparsi o hanno del tutto mutato di aspetto.".

"Si ha l'impressione di affaciarsi a una finestra e di assistere, stupiti e interessati, allo svolgersi in piena vita di istituti e di rapporti, di cui avevamo avuto finora una indiretta conoscenza dai polverosi volumi di Durante e di Bartolo."

E em refôrço da tese salienta: "In particolare il diritto francese, d'importanza preponderante nella formazione dei moderni diritti europei, non ha invece esteso la sua influenza sul diritto: brasiliano, il quale è perció rimasto più attaccato alla sua lontana origine ed ha potuto conservare, più o meno intatti, numerosi istituti del dirito comune che non sono ormai in Europa se non dei ricordi storici (rammento, a titolo d'esempio, l'assenza del principio che per i beni mobili possession vaut titre)."

7. A despeito da divergência apontada em relação ao marco inicial da história do nosso direito, está o professor Liebman de acôrdo em situá-lo também do outro lado do Atlântico, em território da Ibéria, cenário do formidável encontro de raças a que se refere Oliveira Martins e onde as tres correntes jurídicas, romana, germânica e canônica, confluiram e combinaram-se, para formar o caudaloso rio de que emergiu mais tarde o direito das naçôes modernas (Martins Junior, ob. cit., p. 51).

Como se vê, para determinar a origem do direito brasileiro, diluem-no todos os seus historiadores no direito português, atribuindo a ambos o mesmo berço.

8. A península ibérica deve ter sido inicialmente povoada pelos ibéricos, que lhe deram o nome, povo emigrado. da Asia, em época incerta, em demanda do ocidente pelo 
sul da Europa ou pelo norte da Africa. A êles juntaram-se os célticos, produzindo os celtiberos, cujas principais tribus foram as dos cantabros, asturios, vasconios, calaicos e lusitanos (Reinaldo Porchat, Curso elementar de direito romano, vol. I, p. 25).

Destituida de fundamento não é, porém, a hipótese de a êstes povos haverem precedido, na ocupação das terras do Ebro, algumas tribus hebraicas. Fenícios, Tuaregs, Berberes ou outros povos de origem semita, devem ter-se ali estabelecido antes da chegada dos célticos, que já encontraram o grande rio da terra batisado com o nome de Ebro, homenanagem talvez dos primeiros habitantes à velha cidade nacional sagrada do Hebron, em que Davi se coroara rei de Israel. Autores de altíssima linhagem intelectual participam desta opinião. Martins Junior e Siqueira Ferreira atribuem-na ao autor de Hispania illustrata,, " para quem os primitivos povoadores da península seriam os hebreus que constituiam as tribus dos Cetubales, Igletas e Sicanos. Oliveira Martins (História da civilização ibérica, 5. ${ }^{a}$ edição), partindo do elemento filológico, baseado na teoria de Humboldt e das indagações antropológicas de Haekel, Mueller e Broca, chega à conclusão de que é verossímel hajam os primitivos habitantes da Hispania tido origem nos povos da Africa setentrional. Os etnólogos - refere o historiador luso - já entre os séculos XXII e XX antes de Cristo, assinalam a colonização dos fenícios, "incontestados semitas, na Hespanha". Alexandre Herculano (História de Portugal, $4 .^{a}$ ed., $10^{\circ}$ vol., p. 11), cita as indagações de Pereira de Figueiredo acêrca das origens đà populaçăo ibérica, remontando a 1400 anos antes da era cristã. Fidelino de Figueiredo, finalmente, em seu livro Espanha, considera Tubal ou Tubalcain o fundador da população peninsular. Tubal. que era filho de Lamech e irmão de Noé, teria emigrado quando Deus castigou com a dispersão pela terra os povos que $O$ afrontaram com a audácia da Torre de Babel. A cidade

(*) André Sichott, filólogo holandês, morto em 1627. 
portuguêsa de Setubal tiraria o seu nome, assim, do grande hebreu, "que primeiro dera leis e justiça às terras da Espanha".

Em favor da tese, além dos elementos fornecidos pela filosofia e pela antropologia, não devem ser desprezados os de ordem psicológica fornecidos pelo notavel substractum religioso, que caracteriza o fundo da alma nacional, e acentuada tendencia popular, em todos os tempos, pelo judaismo.

Em tais condições, a mais remota fonte do direito português há de ter sido a legislação mosaica, muito embora não subsistam quáisquer documentos que confirmem a hipótese, como também, na formação do seu espirito juridico, se desconhecem traços da influência céltica e mesmo dos gregos da Fócida e dos cartagineses de Amilcar e Asdrubal, os quais sucessivamente ocuparam a península.

9. Documentalmente, o direito só aparece na Ibéria depois da segunda guerra púnica, em que Roma venceu Cartago e apoderou-se da Espanha por Scipião, o Africano, logo dominada na qualidade de provincia romana e regida pelas formulae provinciae, que a República editava para os povos de sua conquista.

Dividida, a princípio, por Julio Cesar, em duas províncias - a Citerior e a Ulterior - separadas pelo rio Ebro, passou a península mais tarde, por ato de Augusto, a dividir-se em três - a Tarraconense, a Lusitania e a Bética, governadas as duas primeiras por um legado do imperador - legatus augustalis - e a última por um proconsul de nomeação do senado. Posteriormente, também a Bética foi promovida a província imperial e, quando Deocleciano dividiu o império em quatro grandes prefeituras, entrou a Espanha, com as sete províncias de que se compunha, a integrar a prefeitura das Gálias.

A Lusitania, segundo informação de Rafael de Labra, citada por Martins Junior (História do direito nacional, p. $60)$, "fué regida al principio por las leyes que las provincias 
romanas recibian del pueblo-rey cuando eram declaradas tales provincias; por las que se expediam despues expresamente para su gubierno; y finalmente por los edictos de sus magistrados próprios, cuya colección se apelidó Edicto provincial" (Portugal y sus codigos).

Era o direito emanado de Roma. Não era, porém, o jus civile romano, a que somente os cidadãos romanos tinham direito e que só muito mais tarde, sob Caracala, é que se estendeu a todos os súditos livres do império, inclusive nas províncias do exterior.

Regia-se a província ibérica, assim, pelo jus civile de Roma, quando, no século $\mathrm{V}$, em seguida à queda do império romano do ocidente, é o território invadido pelos bárbaros provindos das margens do Báltico, aos quais Geroncio, então governador da Espanha, franqueara a passagem dos Pirineus. Vândalos, suevos, álanos e silingos apossaram-se da península e nela permaneceram em estado de anarquia, praticamente até a eleição de Wallia.

Escreve Oliveira Martins (ob. cit., p. 82): "Poucos anos durou esse estado de anarquia a que a primeira invasão reduzira a Hespanha. Wallia, eleito em 45 rei dos visigodos, pactua a paz com o imperador Honorio, tomando sôbre si o encargo de restabelecer a ordem na peninsula, sob garantia de uma parte dela para os romanos. Deste pacto resultou a expulsão dos vândalos para a Africa; mas não a dos alanos, nem a dos suevos que, no meio das convulsões da guerra, conseguiram fixar-se na Galiza e manter uma independencia, a que, só em 584, Leovigildo pôde pôr termo."

Com o estabelecimento da monarquia visigótica, sensiveis modificações teve de sofrer o direito dos povos conquistados, em face das leis e costumes do invasor, não obstante o seu espírito de tolerância para com a legislação dos vencidos. A Espanha continuou a reger-se, assim, pelos antigos usos e leis romanos, pouco a pouco, naturalmente influenciados pelo direito germânico, de onde a necessidade de ser feita uma compilação da matéria no interêsse do 
povo, cometida a tarefa a vários jurisconsultos romanos, sob. a direção de Goyarico, por ordem do rei Alarico II.

o Breviarium Alaricianum ou Aniani, por ter sido êste referendário real quem subscreveu os exemplares enviados aos cames palatti, é extrato dos códigos gregoriano, hermogeniano e teodosiano, compreendendo ainda algumas novelas posteriores e os escritos de Gaio, Paulo e Papiniano.

Por mais de um século vigorou na península a dualidade de direitos: enquanto os vencidos se regiam pelo código de Alarico, os visigodos se governavam pelas leis germânicas. Para obviar aos inconvenientes do fato, Leovigildo e Recaredo cuidaram de unificar o direito num só código, a ser imposto como lei geral do império visigótico a todos os seus súditos. A esta compilação, de 350 capítulos, acresceu depois o rei Chindaswindo, em 642, as leis posteriores, compondo novo código, dividido em 12 livros e 570 artigos, confirmado e aumentado por seu filho, Receswinto e, afinal, em 693, no reinado de Egica, revisto pelo $16 .^{\circ}$ concílio de Toledo e promulgado com o nome de Codex legum ou Lex visigothorum, cuja tradução em espanhol recebeu o nome de Fuero juzgo ou Libro de los jueces ou Forum judicum e constitue o primeiro código da Ibéria, na opinião de Maynz a base do direito nacional da península

10. O Fuero juzgo, ou lei germânica dos visigodos, compreendia, em 12 livros, grande número de disposições do direito romano, com as modificações introduzidas pelos costumes dos invasores, como por exemplo a instituição dotal e o regime de bens no casamento, amalgamadas com as antigas leis germânicas, tendo a matéria sistematicamente organizada e subordinada "a um plano geral e a idéias propriamente jurídicas" (Oliveira Martins, ob. cit., p. 93).

E marcante, no notavel monumento legislativo, a influência da igreja católica, detentora, na época, do poder político, que lhe grangeara a conversão ao cristianismo de Recaredo e dos subsequentes reis visigodos. Todo êle e obra do clero espanhol, que se tornara, aos poucos, o ver- 
dadeiro intérprete político da nação, exercendo, através dos concílios, a função de legislador do império. "A lei estatui dito código, traindo a sua origem religiosa - é o êmulo da divindade." E a seguir: "Ela é o mensageiro da justiça e soberana da vida; rege as condições e as idadades; impõe-se aos homens e às mulheres, aos moços e aos velhos, aos sábios e aos ignorantes, aos cidadãos e aos camponezes; e não defendem nenhum interêsse particular, porque protege e defende o interesse comum de todos os homens."

Foi tal lei a que regeu por vários séculos a Espanha, resistindo à invasão sarracena e chegando intacta, no século XII, à independência do condado portucalense - como passara a chamar-se a antiga Lusitania - em seguida à esmagadora derrota dos mouros por Afonso Henriques na batalha do campo de Ourique (25 de julho de 1139), com quem surge a nação portuguêsa, logo reconhecida e confirmada pela Santa Sé, em bula de Inocêncio II.

Recorramos ainda uma vez à autoridade de Martins Junior: "Começa nesta data a existência própria do organismo nacional português, desde então politicamente diferenciado. Os portucalenses vão ter daí por diante as suas instituições peculiares, vão desenvolver-se por si como personalidade consciente, campenetrada dos seus elementos de vida e da justiça de suas aspirações. Vejamos como se realizou isto na esfera da atividade social que nos preocupa, isto é, no direito" (ob. cit., p. 70).

Salienta a sobrevivência do Fuero juzgo, aliás expressamente confirmado por D. Bermudo, pelas côrtes de Oviedo e pelo concílio de Coiança, já na primeira metade do século XI e acrescenta: "Nestas condições era natural que Portugal encetasse sua existência como nação autonoma sob o influxo do mesmo direito." Reconhece, entretanto, que Portugal, "quer antes quer logo depois de sua ereção em reino", além das disposições do Código visigótico, teve como leis "os Canones dos concílios, isto é, as prescrições do direito canônico em formação." 
"Mas - adverte - é claro que após os acontecimentos de 1139, as coisas deviam tender a modificar-se. Um novo direito escrito ia naturalmente nascer para o novo reino, confirmando, ratificando os usos e costumes locais ou revogando-os por meio de leis de alcance nacional."

Inicia-se na história do direîto português o período realmente nacional, que abrange duas fases distintas: a da legislação foraleira e a das leis gerais. Com os forais nasce, portanto, o genuino direito português, traduzindo o espírito jurídico inconfundivel da nova nacionalidade.

11. Não, há, efetivamente, como filiar o direito foraleiro às leis anteriores.

$O$ foral é direito autóctone, genuinamente portuguès.

Caracteriza-o, a despeito das diferentes acepções em que a expressão costuma ser estudada, a sua origem eminentemente municipal de verdadeira carta de concelho, où lei de constituição dos concelhos ou municípios. Vale dizer: estatuto local baseado nos costumes não-escritos de cada povoação, contendo os seus encargos e os seus direitos.

As cartas de foral, ensina Oliveira Martins (ob. cit., p. 180), "registravam os usos preestabelecidos e exprimiam os termos de concordata ou protocolo entre dois verdadeiros poderes: o senhorio (do rei, do conde ou da igreja) e o concelho."

A história do direito português dispensa, conseguintemente, o trabalho de recuar no tempo para a plantação do marco inicial em qualquer outra época: começa quando a nação realmente começou a ter as suas leis.

O direito comum, oriundo na Europa medieval da coexistência, lado a lado, dos três grandes códigos - romano, germânico e canônico - influenciou, fortemente, a formação juridica de todos os povos europeus, sem no entanto impedir - como assinala o professor Liebman - que organizasse cada qual dêles o seu direito peculiar, inteiramente distinto do primitivo direito comum e de que não conservam a mínima reminiscência. Um povo tem direito próprio, 
quando aquêle sob cujo império atinge a maturidade jurídica perde as características de dominação estranha e retrata, com fisionomia nacional, os costumes da sociedade que surge.

Alexandre Herculano, em sua monumental História de Portugal, toma como ponto de partida a invasão muçulmana e a independência do reino de Leão, censurando o excessivo "gosto da erudição clássica" que levou alguns historiadores portuguêses ao "improbo e inutil trabalho de encherem grossos volumes com os sucessos reais ou imaginários de sucessão de séculos anteriores à existência da nação."

Idêntica a orientação seguida por Esmein. Na sua história do direito francês, entende o professor da Faculdade de Direito de Paris, com aplausos de Saleilles, não ser necessário dar aos seus alunos como introdução ao estudo da história do direito pátrio as origens, religião e costumes da Gália céltica, preferindo partir da Gália já romanizada, em plena fase histórica (apu'd Oliveira Martins, ob. cit., p. 54).

Por que adotar método diferente em relação ao Brasil?

12. Os portuguêses, que desembarcaram na terra descoberta por Pedro Alvares Cabral, não a encontraram desabitada. Ao contrário, nela já viviam, organizadas embora em sociedades primitivas, diferentes nações, regendo-se por nórmas comuns de comportamento, de obrigatoriedade geral, reveladoras de sua subordinação a direito elementar não legislado. Principalmente em matéria de direito das gentes, não é possivel negar às tribus, que povoavam o Brasil, a observância de princípios característicos de estado jurídico de outros povos de mais adiantada civilisação.

Glasson observa, em seu estudo "Les institutions primitives au Brésil", notavel semelhança entre o instituto da hospitalidade e a prática de preceder à declaração de guerra o lançamento de uma flexa sôbre o território do inimigo, rigorosamente observadas pelos nossos aborigenes e correspondentes solenidades do antigo direito romano. 
Os primeiros colonizadores também não vieram sós. Com êles, suas familias, bens e costumes, devem ter logo aportado aqui os escravos trazidos da África. Pelo menos a outorga de poderes extraordinários, contida nas cartas de doações das capitanias, incluindo o de morte dos escravos, autoriza a conclusão de que êstes hajam sido trazidos cedo para a terra a ser desbravada.

Oriundos da gleba africana, é provavel que os negros escravizados possuissem, na sociedade em que os foi achar a fôrça do preador cruel, algumas instituições rudimentares ou costumes coletivos denunciadores de evolução juridica. Devem ter, porém, perdido completamente a lembrança dêles ao primeiro contacto com os grupos sociais de maior civilização. Não exerceram, por isso, influência ialguma tanto sôbre o direito português da metrópole, quanto sôbre o que se transportava para o Brasil.

A nacionalidade, que iria nascer do cruzamento das três raças encontradiças em solo americano, se conseguiu amalgamar no pigmento da epiderme e nas tendências psíquicas a herança natural recebida, não teve a sua formação jurídica influenciada senão e exclusivamente pelo direito de uma delas.

Só o direito português responde pelo nascimento do direito nacional, eliminado o fator indigena, inteiramente, da competição travada para tal resultado.

Era fatal que isso acontecesse.

destino das civilizações de mais elevado grau impôrem os seus institutos às que lhes são espiritualmente inferiores, ainda que por estas politicamente dominadas.

Já vimos, na península ibérica, desaparecer totalmente todo e qualquer vestígio do direito celtibérico ou mesmo cartaginês ante o predomínio cultural das regras emanadas de Roma, bem como sobreviver o direito visigótico à devastação das tropas de Musa e Taric, através do longo período da ocupação moura. 
Nem se deve a outra lei o sêlo que, a despeito das seculares incompatibilidades que separam alemães e francêses, o código de Napoleão imprimiu no direito civil alemão.

13. Parece-nos, diante do que fica expôsto - suplicada prévia excusa à audácia do cometimento - dever-se cravar o marco inicial da história do direito nacional no momento em que o direito português não seja apenas o direito reinícola vigente no Brasil, mas passe a revestir o carater de direito próprio da colónia distante, editado na conformidade de seus legítimos interesses nacionais.

Ao tempo do descobrimento, o direito português havia sido codificado graças ao paciente trabalho dos jurisconsultos João Mendes e Rui Fernandes, que el rei Afonso V fez publicar e lhe tomou o nome.

D. Manuel, subindo ao trôno em 1495, não resistira à tentação de rever as Ordenações afonsinas, não tanto pela vaidade de também ligar o seu nome ao de grande código legislativo, como principalmente, na opinião de Teófilo Braga (História do direito português), pelo propósito de imprimir sistemática unidade ao direito civil e político, através da refórma dos forais, em que já vinham trabalhando, desde 1497, os juristas João Boto, João Façanha e Fernão de Pina.

Desta missão foram incumbidos o chanceler-mór do reino, doutor Rui Boto, o desembargador Rui da Grãa e o doutor João Cotrim, corregedor da Côrte, que dela se desincumbiram ao cabo de sete anos; mas, verificado que a obra apresentava falhas, foi ela submetida à revisão de novos jurisconsultos, sendo as Ordenações manuelinas publicadas afinal em substituição às Afonsinas, no ano de 1521.

Morto D. Manuel, a corôa passou a D. João III, sob cujo reinado é que praticamente tem início a colonização do Brasil. Em vários pontos o monarca modificou por leis isoladas as Ordenações de seu antecessor, além de reformar $a$ ordem do processo, rever o regimento dos desembargadores do Paço e o da Casa da Suplicação e de criar a Mesa 
da Consciência e Ordem. E', pois, sob a égide das modificações decretadas por D. João III, das cartas régias e dos forais expedidos em relação ao Brasil, que o direito pátrio começa a formar-se. Embora a legislação da metrópole fosse, em matéria de direito privado, a reguladora exclusiva das relações dos súditos portuguêses no continente ou nas colónias de além-mar, desde logo os interesses da corôa em consolidar a conquista ditaram alterações, inclusive no direito substantivo, v. g., quanto ao regime da propriedade territorial e das sucessões, que deram à lei feição nitidamente brasileira. Modificações não menos notaveis experimentou o direito público, diante dos poderes excepcionais conferidos aos donatários das capitanias e das prerrogativas de jurisdição e alçada especiais que lhes eram atribuidas, com funda alteração, assim, do direito adjetivo também, quer no processo civil, quer no criminal.

Com a dominação espanhola e a circunstância de as conclusões do concílio de Trento haverem sido aceitas e proclamadas sem restrição pelas leis de Portugal, sentiu Felipe I a necessidade de reformar as Ordenações manuelinas, a fim de que o direito positivo do reino perdesse o antigo sentido romanista em favor de maior realce do direito canônico.

A restauração da monarquia portuguêsa, a despeito da hostilidade nacionalista natural contra o código oriundo do poder estrangeiro, não impediu que as Ordenações filipinas vencessem a oposição das Côrtes, desencadeada no dia seguinte ao da aclamação de D. Joâo IV e continuassem por mais de dois séculos a reger Portugal e durante quase três vigorasse no Brasil o seu Livro IV, sôbre direito civil. Cinquenta anos antès do código civil brasileiro, já o velho direito português fôra substituido na metrópole pelo código civil português, de $1 .^{\circ}$ de julho de 1867 .

14. Resta-nos agora indagar das origens do nosso direito constitucional. 
O professor Liebman, na publicação a que nos referimos, situa-lhe a fonte no direito norte-americano.

"Per riassumere in una formula semplice e generale la derivazione stórica dei diritti latino-americani, - escreve o ilustre catedrático - si può dire che il diritto costituzionale e l'organizzazione amministrativa sono fondalmente ispirati al modello nordamericano. Il fatto si spiega ricordando che l'independèzza delle nazioni del continente si è affermata nei primi decenni del secolo scorso nel nome di un ideale americano, con un moto di ribellione e di allontanamento delle patrie d'origine, accusate di opprimere e di sfruttare le loro colonie di oltre Atlantico."

Não se nos afigura, data venia, ajustar-se à história esta conclusão do jurista italiano.

O nosso direito administrativo, eminentemente municipalista, nasceu, como acabamos de mostrar, confundindo-se nêle, de acôrdo com a orientação da época, as disposições de ordem judiciária, em as cartas régias de doação das capitanias e teve seu mais duradouro fundamento nos livros I e II das Ordenações.

Quanto ao ideal constitucionalista do povo brasileiro, não é possivel obscurecer a influência exclusiva da revolução norte-americana, que já se assinalara, de modo insofismavel, no pensamento orientador da Inconfidência mineira: Tiradentes, ao ser preso, tinha consigo um exemplar da Constituição votada em Filadélfia havia pouco mais de dez anos.

Isto, porém, a nosso sentir, não autorizava a afirmação de que o direito constitucional brasileiro se haja fundamentalmente inspirado no modêlo norte-americano. $O$ constitucionalismo irradiado da convenção continental, que se reunira em 1774 e dera ao mundo em 1777 a primeira constituição escrita, não só aos brasileiros inspirou na luta pelas reivindicações democráticas, mas a todos os povos esmagados sob o poder absoluto dos reis de direito divino, a começar do francês, a cuja revolução comunicou espírito vivificador. Mas o direito constitucional, concretizado na Carta, que em 
1824 nos outorgou o mesmo príncipe que logo depois faria também de Portugal nação constitucionalizada, êsse é no direito inglês - fonte, aliás, do próprio direito norte-americano - que funda as suas mais sadias raízes.

A república, orientada na propaganda e nos primeiros passos por políticos formados no culto das instituições dos Estados Unidos, é inegavel haver copiado, na estruturação do estado nascente, a fórma atribuida pelos convencionais de Filadélfia ao estado que êles criaram.

Não se confundem, todavia, na essência e nas origens, ambas as fórmas estatais.

A federação norte-americana é realidade jurídica, embora haja saido das sessões secretas da Convenção, com surpreza completa para os estados que ali se representavam. Era estado compôsto, que surgia no moderno direito público, mercê de pacto solêne de união indissoluvel assinado por estados, que até aquêle momento se consideravam soberanos, sob a inelutavel coacção de fatores economicos, determinada pela guerra da independência (cf. Charles Beard, A, $n$ economic interpretation of the constitution of the United States, New York, 1947 e Econamic origins of Jeffersonian Democracy, New York, 1949).

No Brasil, o estado federal concretizou unicamente o velho anseio de autonomia administrativa, com que sempre sonharam as províncias do império, cumprindo a vocação descentralizadora com que a pátria nascera sob as capitanias e os primeiros govêrnos gerais.

Em que pese, pois, a erronea técnica contida no art. $1 .^{\circ}$ da atual Constituição, o Brasil, estado unitário, a partir da independência da província Cisplatina não poderia nunca, cientificamente, passar a constituir federação. Os constituintes de 1891 tanto reconheceram esta impossibilidade jurídica, que, em toda a Carta de 24 de fevereiro, nenhuma vez sequer empregaram tal designação, usando, com maior propriedade, a fórmula nova em direito: "República federativa". 